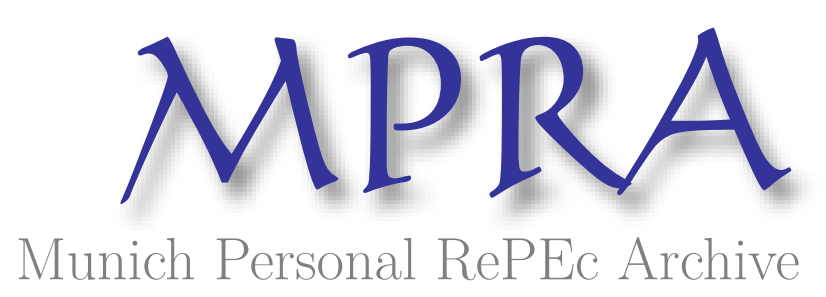

\title{
The predictive relationship between exchange rate expectations and base metal prices
}

Pincheira, Pablo and Hardy, Nicolas

Universidad Adolfo Ibáñez, Universidad Finis Terrae

9 October 2018

Online at https://mpra.ub.uni-muenchen.de/89423/

MPRA Paper No. 89423, posted 09 Oct 2018 15:31 UTC 


\title{
The predictive relationship between exchange rate expectations and base metal prices ${ }^{\text {th }}$
}

\author{
Pablo Pincheira Brown ${ }^{1}$ \\ School of Business, Universidad Adolfo Ibáñez \\ Nicolás Hardy \\ School of Business and Economics, Universidad Finis Terrae
}

August 2018

\begin{abstract}
In this paper we show that survey-based-expectations about the future evolution of the Chilean exchange rate have the ability to predict the returns of the six primary non-ferrous metals: aluminum, copper, lead, nickel, tin and zinc. Predictability is also found for returns of the London Metal Exchange Index. Previous studies have shown that the Chilean exchange rate has the ability to predict copper returns, a world commodity index and base metal prices. Nevertheless, our results indicate that expectations about the Chilean peso have stronger predictive ability relative to the Chilean currency. This is shown both in-sample and out-of-sample. By focusing on expectations of a commodity currency, and not on the currency itself, our paper provides indirect but new and strong evidence of the ability that commodity currencies have to forecast commodity prices. Our results are also consistent with the present-value-model for exchange rate determination.
\end{abstract}

Keywords:

Forecasting, commodities, prices, univariate time-series models, out-of-sample comparison, exchange rates, copper, primary non-ferrous metals JEL: C52, C53, G17, E270, E370, F370, L740, O180, R310.

\footnotetext{
${ }^{\star}$ We thank Andrea Bentancor and participants of the 2018 version of the Meetings of the Society of Chilean Economists for valuable comments. Any errors or omissions are responsibility of the authors.

${ }^{*}$ Corresponding author: Pablo Pincheira Brown.

${ }^{1}$ Avenida Diagonal Las Torres 2640, Edificio C, Oficina 521-C, Peñalolén, Santiago. Chile. Tel.: +56 2 23311489.
} 


\section{Introduction}

In this paper we show that expectations about the future evolution of the Chilean exchange rate have the ability to predict the returns of the six primary non-ferrous metals: aluminum, copper, lead, nickel, tin and zinc. Predictability is also found for returns of the London Metal Exchange Index (LME Index) ${ }^{2}$. Our results are consistent with the present-valuemodel for exchange rate determination and provide indirect but new evidence of the ability that commodity currencies have to forecast commodity prices.

In the last years, a growing literature has explored the empirical validity of the present value model for exchange rate determination. As shown by Campbell and Shiller (1987) and Engel and West (2005), one of the key implications of this model is that exchange rates should Granger-cause their fundamentals. Two papers evaluating this implication for traditional fundamentals in the exchange rate literature, are Engel and West (2005) and Hsiu-Hsin and Ogaki (2015). None of them show very enthusiastic results. For instance, Engel and West (2005) mention that "In summary, while the evidence is far from overwhelming, there does appear to be a link from exchange rates to fundamentals, going in the directions that exchange rates help forecast fundamentals." Engel and West (2005) page 507. Hsiu-Hsin and Ogaki (2015) find even weaker results when using a residual-based bootstrap to test Granger causality from exchange rates to fundamentals. They use the same database and econometric environment used by Engel and West (2005). Interestingly, they also mention that "...studies that help to explore the causality relation from exchange rates to fundamentals could be a priority for the future research", Hsiu-Hsin and Ogaki (2015) page 205.

A related strand of the literature has focused on one particular type of fundamental for some set of currencies. This literature analyzes the case of commodity exporting countries like Australia, Canada, Chile, New Zealand and South Africa. Given that the trade balance of these countries is heavily influenced by commodity prices, it is also expected that their currencies may be influenced by them as well. According to the present-value-model for exchange rate determination, if a given commodity price is an important driving force for a given exchange rate, then there should be Granger causality from that exchange rate to the relevant commodity price. Chen, Rossi and Rogoff (2010) is an influential work exploring this relationship, but many others have followed, including Chen, Rossi and Rogoff (2011, 2014), Groen and Pesenti (2011), Gargano and Timmermann (2014), Lof and Nyberg (2017), Ciner (2017) and Pincheira and Hardy (2018). All these papers evaluate directly the predictive ability from commodity currencies to commodity prices with rather mixed results.

One potential problem when testing Granger causality from exchange rate to fundamentals, is that exchange rates are determined by a variety of different economic forces: some expected, some unexpected. Even in commodity exporting countries, other observable and unobservable drivers like interest rate differentials, shocks in import prices or interventions carried out by monetary authorities may play a role in the determination of exchange rates. In principle these other drivers may erode the ability of exchange rates to predict commodity

\footnotetext{
${ }^{2}$ The LME index consideres the following weights: aluminum (42.8\%), copper $(31.2 \%)$, zinc $(14.8 \%)$, lead $(8.2 \%)$, nickel $(2 \%)$ and tin $(1 \%)$.
} 
prices. To partially overcome this shortcoming, in this paper we analyze the predictive relationship between survey-based expectations of commodity currencies and commodity prices. We do so with the hope that survey-based expectations may be free of erratic and unexpected movements in exchange rates generated by noisy traders or institutional agents. By definition, expectations should be free of unanticipated movements in exchange rates, but of course, they should be determined not only by the expected evolution of the relevant commodity price, but also by all the observable and unobservable fundamentals of a given currency. That is the reason why we use the word "partially" in italics.

We focus on one particular country: Chile, which has been traditionally analyzed in the literature and offers a particularly simple case given the strong connection between the Chilean economy and only one commodity: copper. As noted by Pincheira and Hardy (2018), this metal represents about a half of Chilean exports and nearly $45 \%$ of its Foreign Direct Investment (FDI). We consider the Survey of Economic Expectations (SEE) carried out on a monthly basis by the Central Bank of Chile to extract expectations about future developments of the Chilean peso. Extending the work of Pincheira and Hardy (2018), we explore whether these expectations have the ability to predict copper returns and the returns of closely related assets: non-ferrous metals and the LME Index ${ }^{3}$.

Our in-sample and out-of sample analyses provide evidence of predictability from surveybased expectations of the Chilean peso to all six base metals returns including those from the LME Index. Our findings of predictability are in many cases stronger compared to the predictive ability of the Chilean peso itself, probably because survey-based expectations are free of unanticipated movements in exchange rates that are related to other reasons not connected with commodity prices.

The rest of this paper is organized as follows. In section 2 we present our data and forecasting models. In section 3 we present the results of our in-sample and out-of-sample exercises. Finally, in section 4 we present our conclusions.

\section{Data and forecasting models}

We consider monthly data on Chilean exchange rate expectations coming from the Survey of Economic Expectations (SEE) of the Central Bank of Chile. While individual responses of

\footnotetext{
${ }^{3}$ When explaining their approach, Pincheira and Hardy (2018) mention that "Copper is usually considered as belonging to a larger group of metals known as "base metals" or "non-ferrous metals" that, aside from copper, includes, aluminum, lead, nickel, tin and zinc. These metals have some similarities that are described in Roberts (2008, 2009) and Rossen (2015). In particular, they are all used in industrial applications so their demand is expected to be related to world industrial production. More importantly, all these commodities are traded on a daily basis in the London Metal Exchange and they are also connected by the LME Index and the futures contracts linked to it. These linkages, plus the well known comovement in commodity prices reported for instance in West and Wong (2014), lead us to wonder whether the potential relationship between copper and the Chilean peso can also be generalized to the rest of the non-ferrous metals and to the LME Index".
}

Pincheira and Hardy (2018), page 2. 
the survey are not released to the public, the Central Bank of Chile publishes median values between the 10th and 13 th day of the month ${ }^{4}$. The survey asks for nominal exchange rate forecasts at horizons of 2, 11 and 23 months ahead ${ }^{5}$. In this paper we consider the median value of the short run forecasts 2 months ahead, leaving the analysis with long run forecasts as an extension for future research.

Monthly data for all six commodity prices included in the LME Index are also considered. We include data for the LME Index and for the Chilean peso relative to the U.S. dollar as well. Aside from the survey of the Central Bank of Chile, the main source of our data is Thomson Reuters Datastream from which we downloaded the daily close price of each asset. Our daily data are converted to monthly frequencies by sampling from the 15th day of the month. For those particular months in which the 15th day is not a business day, we consider the first daily data available after the 15th day (the observation either of the 16th or the 17th day of the month). We consider mid-month data because we wish to evaluate the ability of the SEE to forecast commodity returns one month ahead. Given that the survey is released between the 10th and 13th day of the month, it is perfectly possible to use this information to build forecasts of commodity returns between the 15th day of month $t$ and the 15th day of month $t+1$.

The starting point of our sample period is determined by data availability on exchange rate expectations. Consequently, our sample period goes from September 2001 until June 2017. This gives a total of 190 monthly observations ${ }^{6}$. This is also a period of almost pure flotation of the Chilean peso, with only a handful of pre-annouced interventions from the Central Bank of Chile that are addressed in Pincheira (2018). Some descriptive statistics of our series are found in Table A1 in the appendix.

Our econometric specifications are quite simple. They are inspired in the benchmarks used by Chen, Rossi and Rogoff (2010) and by a vast literature that has shown that either the Random Walk (henceforth RW) or simple autoregressions are usually difficult benchmarks to beat when forecasting asset returns ${ }^{7}$. Our in-sample and out-of-sample analyses at the monthly frequency are based on the following simple specifications:

\footnotetext{
${ }^{4}$ http://www.bcentral.cl/en/expectativas-economicas. (in spanish)

${ }^{5}$ The exchange rate is defined as the amount of Chilean pesos needed to buy 1 American dollar in the domestic market.

${ }^{6}$ In terms of one period returns, we have 189 monthly observations.

${ }^{7}$ Examples include the articles by Meese and Rogoff (1983), Clark and West (2006), Chenn, Rossi and Rogoff (2010, 2014), Lof and Nyberg (2017), Groen and Pesenti (2011), Buncic and Moretto (2015) and Goyal and Welch (2008) to mention a few.
} 


$$
\begin{array}{ll}
\hline \text { 1: } & \Delta \ln \left(C P_{t}\right)=c+\beta \Delta \ln \left(S E E_{t-1}\right)+\rho \Delta \ln \left(C P_{t-1}\right)+\varepsilon_{1 t} \\
\text { 2: } \quad \Delta \ln \left(C P_{t}\right)=c+\beta \Delta \ln \left(S E E_{t-1}\right)+\varepsilon_{2 t} \\
\text { 3: } \quad \Delta \ln \left(C P_{t}\right)=\beta \Delta \ln \left(S E E_{t-1}\right)+\varepsilon_{3 t} \\
\text { Source: Authors' elaboration }
\end{array}
$$

where

$$
\begin{aligned}
\Delta \ln \left(C P_{t}\right) & \equiv \ln \left(C P_{t}\right)-\ln \left(C P_{t-1}\right) \\
\Delta \ln \left(S E E_{t}\right) & \equiv \ln \left(S E E_{t}\right)-\ln \left(S E E_{t-1}\right)
\end{aligned}
$$

$C P_{t}$ stands for "Commodity Price" and represents the generic predictand at time $t$, which in our case represents the price of aluminum, copper, lead, nickel, tin, zinc and the LME Index. Similarly, $S E E_{t}$ represents the expectations of the Chilean peso available at the Survey of Economic Expectations at time $t$. Finally, $\varepsilon_{i t}$ represent error terms.

We also explore some specifications including one lag of Chilean exchange rate returns. This is helpful to evaluate if there is redundant information in the survey, relative to that contained in lags of Chilean peso returns. Consequently, we also consider the following specifications

Table 2: Specifications with Chilean Peso Returns

$$
\begin{aligned}
& \text { 4: } \quad \Delta \ln \left(C P_{t}\right)=c+\beta \Delta \ln \left(S E E_{t-1}\right)+\rho \Delta \ln \left(C P_{t-1}\right)+\gamma \Delta \ln \left(E R_{t-1}\right)+\varepsilon_{t} \\
& \text { 5: } \quad \Delta \ln \left(C P_{t}\right)=c+\beta \Delta \ln \left(S E E_{t-1}\right)+\gamma \Delta \ln \left(E R_{t-1}\right)+\varepsilon_{t} \\
& \text { 6: } \quad \Delta \ln \left(C P_{t}\right)=\beta \Delta \ln \left(S E E_{t-1}\right)+\gamma \Delta \ln \left(E R_{t-1}\right)+\varepsilon_{t} \\
& \text { Source: Authors' elaboration }
\end{aligned}
$$

where

$$
\Delta \ln \left(E R_{t}\right) \equiv \ln \left(E R_{t}\right)-\ln \left(E R_{t-1}\right)
$$

and $E R_{t}$ stands for "Exchange Rate". For specifications 1-6 in Tables 1-2, we consider the following null hypothesis $H_{0}$ :

$$
H_{0}: \beta=0
$$

Our null hypothesis $H_{0}$ posits that exchange rate expectations have no role in predicting commodity returns. We test this hypothesis both in-sample and out-of sample focusing on one-step-ahead forecasts only, leaving the analysis of multistep ahead forecasts as an extension for future research.

In-sample evaluations are simply carried out using a t-statistic. For out-of-sample evaluations we use the ENCNEW test proposed by Clark and McCracken (2001) and also used by Chen, Rossi and Rogoff (2010) and Pincheira and Hardy (2018). This test has a non-standard 
asymptotic distribution, but critical values for one-step-ahead forecasts are available in Clark and McCracken's (2001) paper. In general, the asymptotic distribution of the ENCNEW test is a functional of Brownian motions depending on the number of excess parameters of the nesting model, which is 1 in our regressions, the scheme used to update the estimates of the parameters: either rolling, expanding or fixed; and the parameter $\pi$ defined as the limit of the ratio $P / R$, where $P$ is the number of one-step-ahead forecasts and $R$ is the size of the first estimation window used in the out-of-sampe analysis. See Clark and McCracken (2001) or West (2006) for further details about the implementation of out-of-sample tests of predictive ability in nested environments.

For our in-sample analysis we estimate our models with all the available observations. For the out-of-sample analysis we split the sample in two windows: an initial estimation window of size $R$ and a prediction window of size $P$ such that $P+R=T$, where $T$ is the total number of observations. To check for robustness, we split our sample in three different ways. First we use one quarter of our observations for initial estimation and three quarters for evaluation. This means that we pick $R=50$ and $P=150$. Second, we split our sample in two halfs, which means $R=100$ and $P=100$. Finally, we also consider a different situation in which we pick aproximately $70 \%$ of our sample for initial estimation and $30 \%$ for evaluation. This means $R=143$ and $P=57^{8}$. We use a rolling scheme to update the estimates of our parameters in the out-of-sample analysis.

\section{Empirical Resuls}

In this section we report in-sample results of equations 1 and 4 in Tables 1 and 2, respectively. We also show results of the ENCNEW out-of-sample test of Clark and McCracken (2001). We start by reporting our in-sample results.

\subsection{In-sample analysis}

Tables 3 and 4 next show estimates of equations 1 and 4 in Tables 1 and 2 . In Table 3 we show results for equation 1, whereas in Table 4 we show results for equation 4 . In both tables we use HAC standard errors according to Newey and West $(1987,1994)$.

\footnotetext{
${ }^{8}$ The shortest initial estimation window spans the period September 2001-October 2005. The second shortest initial estimation window spans the period September 2001-December 2009. The longest initial estimation window spans the period September 2001-July 2013. These choices are partly driven by the table of asymptotic critical values in Clark and McCracken (2001). This table provides critical values for specific values of the ratio $P / R$. We consider three values: 3,1 and 0.4 .
} 
Table 3: Forecasting base metals returns with expectations of the Chilean peso In-sample analysis with monthly data

\begin{tabular}{|c|c|c|c|c|c|c|c|}
\hline & $\begin{array}{c}\text { (2) } \\
\text { Aluminum }\end{array}$ & $\begin{array}{c}\text { (1) } \\
\text { Copper }\end{array}$ & $\begin{array}{c}(5) \\
\text { Lead }\end{array}$ & $\begin{array}{c}\text { (4) } \\
\text { Nickel }\end{array}$ & $\begin{array}{l}\text { (6) } \\
\text { Tin }\end{array}$ & $\begin{array}{c}\text { (3) } \\
\text { Zinc }\end{array}$ & $\begin{array}{c}(7) \\
\text { Lmex }\end{array}$ \\
\hline SEE(-1) & $\begin{array}{c}-0.868 * * * \\
(0.261)\end{array}$ & $\begin{array}{c}-0.754 * * * \\
(0.264)\end{array}$ & $\begin{array}{c}-1.031 * * * \\
(0.341)\end{array}$ & $\begin{array}{l}-0.656 * \\
(0.362)\end{array}$ & $\begin{array}{c}-0.720 * * \\
(0.306)\end{array}$ & $\begin{array}{c}-0.834 * * * \\
(0.300)\end{array}$ & $\begin{array}{c}-0.817 * * * \\
(0.246)\end{array}$ \\
\hline Aluminum(-1) & $\begin{array}{c}-0.179 * * \\
(0.079)\end{array}$ & & & & & & \\
\hline Copper(-1) & & $\begin{array}{c}0.089 \\
(0.088)\end{array}$ & & & & & \\
\hline Lead $(-1)$ & & & $\begin{array}{c}-0.139 * * \\
(0.067)\end{array}$ & & & & \\
\hline $\operatorname{Nickel}(-1)$ & & & & $\begin{array}{l}-0.054 \\
(0.080)\end{array}$ & & & \\
\hline $\operatorname{Tin}(-1)$ & & & & & $\begin{array}{c}-0.070 \\
(0.075)\end{array}$ & & \\
\hline $\operatorname{Zinc}(-1)$ & & & & & & $\begin{array}{l}-0.081 \\
(0.094)\end{array}$ & \\
\hline Lmex $(-1)$ & & & & & & & $\begin{array}{l}-0.047 \\
(0.093)\end{array}$ \\
\hline Constant & $\begin{array}{c}0.002 \\
(0.005)\end{array}$ & $\begin{array}{c}0.007 \\
(0.005)\end{array}$ & $\begin{array}{c}0.009 \\
(0.007)\end{array}$ & $\begin{array}{c}0.003 \\
(0.009)\end{array}$ & $\begin{array}{c}0.009 \\
(0.006)\end{array}$ & $\begin{array}{c}0.007 \\
(0.007)\end{array}$ & $\begin{array}{c}0.006 \\
(0.005)\end{array}$ \\
\hline Observations & 188 & 188 & 188 & 188 & 188 & 188 & 188 \\
\hline R-squared & 0.094 & 0.078 & 0.065 & 0.020 & 0.043 & 0.050 & 0.075 \\
\hline
\end{tabular}

SEE stands for the log difference in exchange rate expectations

Table 3 presents estimates of equation 1 in Table $1 . *{ }^{*} \mathrm{p}<10 \%, * * \mathrm{p}<5 \%, * * * \mathrm{p}<1 \%$

Source: Authors' elaboration.

We see from the first row in Table 3, that our null hypothesis is rejected at the $10 \%$ significance level in all seven cases. Furthermore, it is rejected at the $1 \%$ significance level in the cases of aluminum, copper, lead, zinc and the LMEX. In addition, all the coefficients asssociated to exchange rate expectations are negative, which is consistent with the intuition of a inverse relationship between the Chilean peso and commodity prices (copper price in particular).

A few additional features are worth noticing. First, aside from the case of aluminum and lead, neither the constant term nor the first lag of the asset returns being predicted, are statistically significant. This is consistent with very little autocorrelation in asset returns. Notably, the coefficients associated to the expectations of the Chilean peso are, in general, close to one in absolute value. Finally, the coefficient of determinations are in the range of 2.0\%-9.4\%, being the highest for aluminum and the lowest for nickel. All in all, our results suggest an interesting ability of the expectations of the Chilean peso to predict base metals returns. 
Table 4: Forecasting Base Metals Returns with Expectations of the Chilean Peso Regressions including one lag of Chilean Peso Returns

\begin{tabular}{|c|c|c|c|c|c|c|c|}
\hline & $\begin{array}{c}\text { (2) } \\
\text { Aluminum }\end{array}$ & $\begin{array}{c}(1) \\
\text { Copper }\end{array}$ & $\begin{array}{c}(5) \\
\text { Lead }\end{array}$ & $\begin{array}{c}\text { (4) } \\
\text { Nickel }\end{array}$ & $\begin{array}{l}(6) \\
\text { Tin }\end{array}$ & $\begin{array}{c}(3) \\
\text { Zinc }\end{array}$ & $\begin{array}{c}\text { (7) } \\
\text { Lmex }\end{array}$ \\
\hline$S E E(-1)$ & $\begin{array}{c}-0.862 * * * \\
(0.314)\end{array}$ & $\begin{array}{c}-0.564 * * \\
(0.251)\end{array}$ & $\begin{array}{c}-0.878 * * \\
(0.428)\end{array}$ & $\begin{array}{l}-0.637 * \\
(0.333)\end{array}$ & $\begin{array}{c}-1.066 * * * \\
(0.353)\end{array}$ & $\begin{array}{c}-0.675 * * \\
(0.316)\end{array}$ & $\begin{array}{c}-0.695 * * * \\
(0.259)\end{array}$ \\
\hline$C L P(-1)$ & $\begin{array}{l}-0.008 \\
(0.185)\end{array}$ & $\begin{array}{l}-0.289 \\
(0.252)\end{array}$ & $\begin{array}{l}-0.209 \\
(0.288)\end{array}$ & $\begin{array}{l}-0.025 \\
(0.299)\end{array}$ & $\begin{array}{l}0.460 * \\
(0.235)\end{array}$ & $\begin{array}{l}-0.231 \\
(0.179)\end{array}$ & $\begin{array}{l}-0.191 \\
(0.172)\end{array}$ \\
\hline Aluminum(-1) & $\begin{array}{c}-0.180 * * \\
(0.081)\end{array}$ & & & & & & \\
\hline Copper(-1) & & $\begin{array}{c}0.061 \\
(0.081)\end{array}$ & & & & & \\
\hline Lead $(-1)$ & & & $\begin{array}{c}-0.152 * * \\
(0.068)\end{array}$ & & & & \\
\hline $\operatorname{Nickel(-1)}$ & & & & $\begin{array}{l}-0.056 \\
(0.083)\end{array}$ & & & \\
\hline $\operatorname{Tin}(-1)$ & & & & & $\begin{array}{l}-0.034 \\
(0.075)\end{array}$ & & \\
\hline $\operatorname{Zinc}(-1)$ & & & & & & $\begin{array}{l}-0.102 \\
(0.100)\end{array}$ & \\
\hline Lmex(-1) & & & & & & & $\begin{array}{l}-0.072 \\
(0.086)\end{array}$ \\
\hline Constant & $\begin{array}{c}0.002 \\
(0.005)\end{array}$ & $\begin{array}{c}0.007 \\
(0.006)\end{array}$ & $\begin{array}{c}0.009 \\
(0.007)\end{array}$ & $\begin{array}{c}0.003 \\
(0.009)\end{array}$ & $\begin{array}{c}0.009 \\
(0.006)\end{array}$ & $\begin{array}{c}0.007 \\
(0.007)\end{array}$ & $\begin{array}{c}0.006 \\
(0.005)\end{array}$ \\
\hline Observations & 188 & 188 & 188 & 188 & 188 & 188 & 188 \\
\hline R-squared & 0.094 & 0.085 & 0.068 & 0.020 & 0.060 & 0.054 & 0.079 \\
\hline
\end{tabular}

Results from Table 4 are more striking than those from Table 3. We see that, in spite of the inclusion of one lag of Chilean peso returns, the statistical significance of exchange rate expectations remains almost intact. Our null hypothesis is again rejected at the $10 \%$ significance level in all seven cases. Furthermore, it is rejected at the $1 \%$ significance level in the cases of aluminum, tin and the LMEX and at the $5 \%$ significance level in the cases of copper, lead and zinc. All the coefficients associated to expectations of Chilean peso returns are negative, although in most cases they are slightly lower in magnitude relative to those reported in Table 3 (with tin being the only exception). Notably, in only one case the returns of the Chilean peso are statistically significant (tin) and the coefficient is positive, indicating that most of the action between exchange rates and base metal prices is indeed captured by expectations to the detriment of actual lags of Chilean peso returns. Now some of the coefficients of determinaton are slightly higher, but in general they are all included in the same interval as before: $2.0 \%-9.4 \%$. The lowest coefficient is again achieved for nickel, and the highest for aluminum. 
In summary, in-sample estimates provide evidence of a predictive relationship between the time series on exchange rate expectations and base metal returns. Given that in-sample analyses are prone to overfitting and sometimes are not really adequate to capture predictability in real time, we present next results of an out-of-sample analysis.

\subsection{Out-of-sample analysis}

Tables 5-7 show results of the ENCNEW test of Clark and McCracken (2001) in different out-of-sample exercises. Table 5 shows results when the number of one-step-ahead forecasts is three times the number of observations of the first estimation window $(\pi \equiv P / R=3)$. Table 6 is similar to Table 5 but reports results when the number of one-step-ahead forecasts is the same as the number of observations used in the first estimation window $(\pi \equiv P / R=1)$. Finally, in Table 7 we consider a situation in which the number of one-step-ahead forecasts is $40 \%$ of the number of observations used in the first estimation window $(\pi \equiv P / R=0.4)$. We recall here that we use rolling instead of expanding windows to update parameter estimates. We think that a rolling scheme probably takes better into account potential instabilities that are likely to exist in the data.

Table 5: Forecasting Base Metals Returns with Expectations of Chilean Exchange Rates Out-of-sample analysis in rolling windows of size $\mathrm{R}=48,(\pi \equiv P / R=3)$

\begin{tabular}{c|cccccccc}
\hline \multicolumn{2}{c}{$(1)$} & $(2)$ & $(3)$ & $\begin{array}{c}(4) \\
\text { ENCNEW }\end{array}$ & $(5)$ & $(6)$ & $(7)$ & $(8)$ \\
\hline Benchmark Model & aluminum & copper & lead & nickel & tin & zinc & lmex \\
\hline AR(1) & $16.58^{* * *}$ & $2.55^{*}$ & $6.09^{* * *}$ & -2.73 & $5.30^{* *}$ & $4.34^{* *}$ & $7.48^{* * *}$ \\
\hline RW & $12.38^{* * *}$ & $6.18^{* * *}$ & $3.20^{*}$ & -2.91 & $2.83^{*}$ & $5.83^{* *}$ & $7.45^{* * *}$ \\
\hline DRW & $12.53^{* * *}$ & $6.97^{* * *}$ & $4.30^{* *}$ & -2.35 & $3.40^{*}$ & $5.73^{* *}$ & $8.10^{* * *}$ \\
\hline
\end{tabular}

$10 \%, 5 \%$ and $1 \%$ critical values are 2.322, 3.444 and 5.976 respectively for ENCNEW for one excess parameter.

$\mathrm{P}$ representes the number of one-step-ahead forecasts, $\mathrm{R}$ the sample size of the rolling estimation windows.

The AR(1) benchmark corresponds to model 1 in Table 1 when the coefficient associated to SEE is set to zero. Similarly, the RW and DRW benchmarks correspond to models 2 and 3 in Table 1, respectively, when the coefficient associated to SEE is set to zero

$$
* \mathrm{p}<10 \%, * * \mathrm{p}<5 \%, * * * \mathrm{p}<1 \%
$$

Source: Authors' elaboration. 
Table 6: Forecasting Base Metals Returns with Expectations of Chilean Exchange Rates Out-of-sample analysis in rolling windows of size $\mathrm{R}=95,(\pi \equiv P / R=1)$

\begin{tabular}{|c|c|c|c|c|c|c|c|}
\hline (1) & (2) & (3) & (4) & (5) & (6) & (7) & (8) \\
\hline \multicolumn{8}{|c|}{ ENCNEW } \\
\hline Benchmark Model & aluminum & copper & lead & nickel & $\operatorname{tin}$ & zinc & $\operatorname{lmex}$ \\
\hline $\mathrm{AR}(1)$ & $9.48^{* * *}$ & $2.90^{* *}$ & $7.28^{* * *}$ & $2.11^{* *}$ & $2.45^{* *}$ & $4.51^{* *}$ & $5.75^{* * *}$ \\
\hline RW & $3.66^{* *}$ & $2.98^{* *}$ & $4.27^{* * *}$ & $1.47^{*}$ & $2.22^{* *}$ & $3.38^{* *}$ & $3.79^{* * *}$ \\
\hline DRW & $3.97^{* * *}$ & $3.43^{* *}$ & $4.35^{* * *}$ & $1.75^{*}$ & $1.95^{* *}$ & $3.47^{* *}$ & $4.15^{* * *}$ \\
\hline
\end{tabular}

$10 \%, 5 \%$ and $1 \%$ critical values are 1.210, 1.946 and 3.676 respectively for ENCNEW for one excess parameter.

$\mathrm{P}$ representes the number of one-step-ahead forecasts, $\mathrm{R}$ the sample size of the rolling estimation windows.

The AR(1) benchmark corresponds to model 1 in Table 1 when the coefficient associated to SEE is set to zero. Similarly, the RW and DRW benchmarks correspond to models 2 and 3 in Table 1, respectively, when the coefficient associated to SEE is set to zero

$* \mathrm{p}<10 \%, * * \mathrm{p}<5 \%, * * * \mathrm{p}<1 \%$

Source: Authors' elaboration.

The null hypothesis of no predictability is rejected in the vast majority of the cases at least at the $10 \%$ significance level. This means that we detect predictability against all our three benchmark models, for most of the base metals and also for the LME Index. Actually, rejections of the null are found in 58 of the total of 63 entries in tables 5-7 at the 10\% significance level. Robust evidence of predictability across all three tables and all three benchmarks are found for copper, lead, tin, zinc and the LME Index. Moreover, in many entries of the tables, we reject the null hypothesis at tight significance levels of $1 \%$.

Tables B1-B3 in Appendix B show results of similar out-of-sample exercises when using one lag of Chilean Peso returns as a predictor, instead of one lag of the returns of the Survey of Economic Expectations. While results in tables B1-B3 show some predictability from Chilean Exchange Rate returns to base metal returns, these results are in generally weaker than those shown in Tables 5-7. For instance, rejections of the null at the $10 \%$ significance level are found in 33 of the total of 63 entries in tables B1-B3. Let us recall that when using the survey, we find rejections in 58 of the 63 entries. Finally, while robust evidence of predictability across all three tables and all three benchmarks are found for copper, lead, tin, zinc and the LME Index using the survey as a predictor, in Tables B1-B3 we see that robust predictability is only found for the LMEX when using the Chilean peso as a predictor. 
Table 7: Forecasting Base Metals Returns with Expectations of Chilean Exchange Rates Out-of-sample analysis with rolling windows of size $\mathrm{R}=136(\pi \equiv P / R=0.4)$

\begin{tabular}{c|cccccccc}
\hline \multicolumn{2}{c}{$(1)$} & $(2)$ & $(3)$ & $\begin{array}{c}(4) \\
\text { ENCNEW }\end{array}$ & $(5)$ & $(6)$ & $(7)$ & $(8)$ \\
\hline Benchmark Model & aluminum & copper & lead & nickel & tin & zinc & lmex \\
\hline AR(1) & $2.69^{* * *}$ & $2.10^{* *}$ & $4.06^{* * *}$ & $1.20^{* *}$ & $1.75^{* *}$ & $1.76^{* *}$ & $2.86^{* * *}$ \\
\hline RW & 0.19 & $2.90^{* * *}$ & $2.31^{* * *}$ & $1.22^{*}$ & $2.56^{* * *}$ & $1.68^{* *}$ & $3.06^{* * *}$ \\
\hline DRW & -0.21 & $1.65^{* *}$ & $1.23^{* *}$ & $1.02^{*}$ & $1.44^{* *}$ & $1.09^{*}$ & $1.93^{* *}$ \\
\hline \hline
\end{tabular}

$10 \%, 5 \%$ and $1 \%$ critical values are $0.764,1.161$ and 2.278 respectively for ENCNEW for one excess parameter.

$\mathrm{P}$ representes the number of one-step-ahead forecasts, $\mathrm{R}$ the sample size of the rolling estimation windows.

The AR(1) benchmark corresponds to model 1 in Table 1 when the coefficient associated to SEE

is set to zero. Similarly, the RW and DRW benchmarks correspond to models 2 and 3 in Table 1 , respectively, when the coefficient associated to SEE is set to zero

$$
* \mathrm{p}<10 \%, * * \mathrm{p}<5 \%, * * * \mathrm{p}<1 \%
$$

Source: Authors' elaboration.

We explore next whether the predictive relationship between base metals and exchange rate expectations is overshadowed by the presence of the first lag of Chilean exchange rate returns, just like we do in our in-sample analysis. Tables 8-10 show the ENCNEW statistic when the relevant models are those in Table 2. In other words, when we augment our benchmarks with one lag of monthly returns of the Chilean peso. 
Table 8: Forecasting with Expectations of Chilean Exchange Rates Returns

Benchmarks now include one lag of Chilean exchange rate returns

Out-of-sample analysis in rolling windows of size $\mathrm{R}=48,(\pi \equiv P / R=3)$

\begin{tabular}{c|cccccccc}
\hline \multicolumn{1}{c}{$(1)$} & $(2)$ & $(3)$ & $(4)$ & $(5)$ & $(6)$ & $(7)$ & $(8)$ \\
\hline Benchmark Model & aluminum & copper & lead & nickel & tin & zinc & lmex \\
\hline $\mathrm{AR}(1)+\mathrm{d} \log (\mathrm{ER}(-1))$ & $8.76^{* * *}$ & 0.14 & 1.52 & -1.62 & $8.44^{* * *}$ & 1.90 & $3.07^{*}$ \\
\hline $\mathrm{RW}+\mathrm{d} \log (\mathrm{ER}(-1))$ & $5.18^{* *}$ & 0.83 & 0.82 & -1.75 & $8.57^{* * *}$ & 2.05 & 2.19 \\
\hline $\mathrm{DRW}+\mathrm{d} \log (\mathrm{ER}(-1))$ & $5.42^{* *}$ & 1.15 & 1.13 & -1.25 & $8.77^{* * *}$ & 2.04 & 2.57 \\
\hline \hline
\end{tabular}

$10 \%, 5 \%$ and $1 \%$ critical values are $2.322,3.444$ and 5.976 respectively for ENCNEW for one excess parameter.

$\mathrm{P}$ representes the number of one-step-ahead forecasts, $\mathrm{R}$ the sample size of the rolling estimation windows.

The AR(1) benchmark corresponds to model 4 in Table 2 when the coefficient associated to the SEE

is set to zero. Similarly, the RW and DRW benchmarks correspond to models 5 and 6 in Table 2,

respectively, when the coefficient associated to the SEE is set to zero.

$\operatorname{d} \log (\mathrm{ER}(-1))$ represents the first lag of Chilean exchange rate returns.

$* \mathrm{p}<10 \%, * * \mathrm{p}<5 \%, * * * \mathrm{p}<1 \%$

Source: Authors' elaboration.

Table 9: Forecasting with Expectations of Chilean Exchange Rates Returns

Benchmarks now include one lag of Chilean exchange rate returns

Out-of-sample analysis in rolling windows of size $\mathrm{R}=95,(\pi \equiv P / R=1)$

\begin{tabular}{c|cccccccc}
\hline \multicolumn{1}{c}{$(1)$} & $(2)$ & $(3)$ & $\begin{array}{c}(4) \\
\text { ENCNEW }\end{array}$ & $(5)$ & $(6)$ & $(7)$ & $(8)$ \\
\hline Benchmark Model & aluminum & copper & lead & nickel & tin & zinc & lmex \\
\hline $\mathrm{AR}(1)+\mathrm{d} \log (\mathrm{ER}(-1))$ & $6.44^{* * *}$ & $1.64^{*}$ & $4.81^{* * *}$ & 0.37 & $3.42^{* *}$ & $2.71^{* *}$ & $3.35^{* *}$ \\
\hline $\mathrm{RW}+\mathrm{d} \log (\mathrm{ER}(-1))$ & $3.15^{* *}$ & $1.36^{*}$ & $3.58^{* *}$ & 0.16 & $3.53^{* *}$ & $2.20^{* *}$ & $2.28^{* *}$ \\
\hline $\mathrm{DRW}+\mathrm{d} \log (\mathrm{ER}(-1))$ & $3.30^{* *}$ & $1.47^{*}$ & $3.54^{* *}$ & 0.30 & $3.35^{* *}$ & $2.20^{* *}$ & $2.40^{* *}$ \\
\hline \hline
\end{tabular}

$10 \%, 5 \%$ and $1 \%$ critical values are 1.210, 1.946 and 3.676 respectively for ENCNEW for one excess parameter.

$\mathrm{P}$ representes the number of one-step-ahead forecasts, $\mathrm{R}$ the sample size of the rolling estimation windows.

The AR(1) benchmark corresponds to model 4 in Table 2 when the coefficient associated to the SEE

is set to zero. Similarly, the RW and DRW benchmarks correspond to models 5 and 6 in Table 2,

respectively, when the coefficient associated to the SEE is set to zero.

$\operatorname{d} \log (\operatorname{ER}(-1))$ represents the first lag of Chilean exchange rate returns.

$* \mathrm{p}<10 \%, * * \mathrm{p}<5 \%, * * * \mathrm{p}<1 \%$

Source: Authors' elaboration. 
Table 10: Forecasting with Expectations of Chilean Exchange Rates Returns

Benchmarks now include one lag of Chilean exchange rate returns

Out-of-sample analysis with rolling windows of size $\mathrm{R}=136(\pi \equiv P / R=0.4)$

$(1)$

(2)

(3)

$(4)$

(5)

(6)

(7)

(8)

ENCNEW

\begin{tabular}{c|ccccccc}
\hline Benchmark Model & aluminum & copper & lead & nickel & tin & zinc & lmex \\
\hline $\mathrm{AR}(1)+\mathrm{d} \log (\operatorname{ER}(-1))$ & $2.58^{* * *}$ & 0.73 & $2.83^{* * *}$ & -0.03 & $1.10^{*}$ & $1.10^{*}$ & $1.32^{* *}$ \\
\hline $\mathrm{RW}+\mathrm{d} \log (\operatorname{ER}(-1))$ & $1.64^{* *}$ & 0.68 & $2.34^{* * *}$ & -0.03 & $1.07^{*}$ & $1.13^{*}$ & $1.29^{* *}$ \\
\hline $\mathrm{DRW}+\operatorname{d} \log (\mathrm{ER}(-1))$ & $1.51^{* *}$ & 0.28 & $1.91^{* *}$ & -0.18 & 0.11 & $0.91^{*}$ & $0.85^{*}$ \\
\hline
\end{tabular}

$10 \%, 5 \%$ and $1 \%$ critical values are $0.764,1.161$ and 2.278 respectively for ENCNEW when there is 1 excess parameter.

$\mathrm{P}$ representes the number of one-step-ahead forecasts, $\mathrm{R}$ the sample size of the rolling estimation windows.

The AR(1) benchmark corresponds to model 4 in Table 2 when the coefficient associated to the SEE

is set to zero. Similarly, the RW and DRW benchmarks correspond to models 5 and 6 in Table 2,

respectively, when the coefficient associated to the SEE is set to zero.

$\operatorname{d} \log (\operatorname{ER}(-1))$ represents the first lag of Chilean exchange rate returns.

$* \mathrm{p}<10 \%, * * \mathrm{p}<5 \%, * * * \mathrm{p}<1 \%$

Source: Authors' elaboration.

Results in Tables 8-10 show that the predictive ability of exchange rate expectations is only partially overshadowed by the presence of one lag of Chilean peso returns. As a matter of fact, in more than $63 \%$ of the entries in Tables 8-10, survey-based-expectations are still statistically significant at the $10 \%$ level, indicating that in the majority of the cases, they have additional information relative to the first lag of exchange rate returns. In particular, in the case of aluminum the additional information contained in exchange rate expectations is robust across all three benchmarks and all three out-of-sample exercises.

Results in Tables 8-10 seem more striking when we analyze the reverse situation: whether chilean peso returns have additional information to that already contained in exchange rate expectations. Tables C1-C3 in the appendix show results when testing out-of-sample the following null hypothesis in the models of Table 2 :

$$
H_{0}: \gamma=0
$$

This null hypothesis posits that exchange rate returns have no role in predicting commodity returns beyond that contained in the returns of exchange rate expectations. Results in Tables C1-C3 are overwhelming. Rejection of the null at usual significance levels is only found in 4 entries out of the 63 cells in Tables C1-C3. These 4 cases are always for the same metal: tin.

In summary, results in Tables C1-C3 are fairly consistent with our in-sample results shown in Table 4: Exchange rate expectations seem to overshadow the predictive ability of the Chilean peso over base metal returns, with tin being the only expection. The opposite situation is by 
far less frequent: the Chilean peso only partially overshadows the predictive role of exchange rate expectations.

\subsection{Some Explanations}

Our in-sample and out-of-sample results show, in many cases, a superior predictive performance of the SEE relative to actual Chilean exchage rates. One possible explanation for this relies on the fact that the Chilean peso is highly volatile compared to its expectations (see Table A1), and some of this volatility may not be related to fundamentals. In particular, the role of noisy traders and important institutional players in Chile may be distorting the linkage between exchange rates and fundamentals. For instance, during our sample period, the Central Bank of Chile carried out four episodes of exchange rate interventions that shifted away the evolution of the Chilean peso from fundamentals. In fact there are some interesting charts in Pincheira (2018) showing the successfulness of these interventions in very high frequency. Similarly, other important institutional players in Chile are pension funds. Cowan, Rappoport and Selaive (2008) report that asset allocation by pension funds have the ability to impact the exchange rate both in the short and the long run. As long as these interventions or investment decisions are driven by reasons not directly related to fundamentals, they will introduce movements in the exchange rate that will not help to predict these fundamentals. If these exchange rate movements are not expected by market players, then they will leave unaltered the predictive ability of exchange rate expectations.

In summary, both noisy traders and institutional players can make decisions distorting the linkage between exchange rates and fundamentals. If these decisions are unexpected by the market, then expectations will not be distorted and will preserve their ability to predict fundamentals. 
Table 11: Percentage of rolling windows in which the relevant measure of exchange rate is statistically significant at the $10 \%$ level

Out-of-sample analysis with rolling windows of different sizes: $\mathrm{R}=48, \mathrm{R}=95$ and $\mathrm{R}=136$

\begin{tabular}{|c|c|c|c|c|c|c|c|}
\hline (1) & (2) & (3) & $\begin{array}{c}(4) \\
\text { ENCN }\end{array}$ & (5) & (6) & (7) & (8) \\
\hline \multicolumn{8}{|c|}{ Results for the Survey of Economic Expectations } \\
\hline Size of the window & aluminum & copper & lead & nickel & $\operatorname{tin}$ & zinc & $\operatorname{lmex}$ \\
\hline $\mathrm{R}=48$ & $80 \%$ & $64 \%$ & $74 \%$ & $30 \%$ & $37 \%$ & $70 \%$ & $71 \%$ \\
\hline$R=95$ & $100 \%$ & $100 \%$ & $100 \%$ & $54 \%$ & $98 \%$ & $100 \%$ & $100 \%$ \\
\hline$R=136$ & $100 \%$ & $100 \%$ & $100 \%$ & $48 \%$ & $100 \%$ & $100 \%$ & $100 \%$ \\
\hline \multicolumn{8}{|c|}{ Results for Chilean Exchange Rates } \\
\hline Size of the window & aluminum & copper & lead & nickel & $\operatorname{tin}$ & zinc & lmex \\
\hline $\mathrm{R}=48$ & $44 \%$ & $54 \%$ & $54 \%$ & $26 \%$ & $4 \%$ & $58 \%$ & $57 \%$ \\
\hline$R=95$ & $97 \%$ & $99 \%$ & $92 \%$ & $26 \%$ & $0 \%$ & $98 \%$ & $100 \%$ \\
\hline$R=136$ & $100 \%$ & $100 \%$ & $100 \%$ & $0 \%$ & $0 \%$ & $93 \%$ & $100 \%$ \\
\hline
\end{tabular}

$\mathrm{R}$ represents the sample size of the rolling estimation windows.

Statistical significance of the Survey is measured according to specification 1 in Table 1.

Statistical significance of the Chilean Peso is measured according to specification 1 in Table B4.

Source: Authors' elaboration.

Table 11 provides another perspective that can be helpful to understand why expectations, in some cases, show more predictive power than exchange rates. Each entry in Table 11 displays the percentage of rolling windows, used in our out-of-sample analyses, for which expectations (in the first panel) and exchange rates (in the second panel) are statistically significant at the $10 \%$ significance level. We consider specification 1 in Table 1 for expectations

$$
\Delta \ln \left(C P_{t}\right)=c+\beta \Delta \ln \left(S E E_{t-1}\right)+\rho \Delta \ln \left(C P_{t-1}\right)+\varepsilon_{1 t}
$$

and specification 1 in Table B4 for exchange rates:

$$
\Delta \ln \left(C P_{t}\right)=c+\beta \Delta \ln \left(E R_{t-1}\right)+\rho \Delta \ln \left(C P_{t-1}\right)+u_{1 t}
$$

Results in Table 11 are fairly eloquent as figures in the top panel are always equal or higher than the comparable figures in the second panel. This means that the statistical significance of expectations is more rubust relative to the statistical significance of exchange rates. For some metals, like copper, these differences do not seem to be gigantic, but for some other metals, like tin, differences are overwhelming in favor of expectations. All in all, results in Table 11 are consistent with our out-of-sample results, and also with the qualitative explanations given previously, although of course, they are not a proof of them.

\section{Summary and Conclusions}

In this paper we show that expectations of the Chilean exchange rate have the ability to predict the returns of the six primary non-ferrous metals: aluminum, copper, lead, nickel, tin 
and zinc. Predictability is also found for returns of the London Metal Exchange Index (LME Index). This is shown using both in-sample and out-of-sample analyses. Our results indicate that, in many cases, exchange rate expectations have stronger ability to predict commodity returns relative to the Chilean exchange rate. These findings are consistent with the presentvalue-model for exchange rate determination and provide indirect but new evidence of the ability that commodity currencies have to forecast commodity prices.

As mentioned in Pincheira and Hardy (2018), it is important to remark here that predictability of base metal prices is not necessarily in conflict with the so called "efficient market hypothesis". As long as the potential returns obtained using our forecasts are not abnormal, efficient markets and predictability may peacefully coexist. See also Engel and West (2005) for further details.

Our results are important, as only a few relatively recent papers have reported results showing predictability from exchange rates to fundamentals. According to our findings, this type of relationship may be better exploited through the use of exchange rate expectations, that are free from the volatility induced by noisy traders and some institutional players.

An interesting avenue for future research could extend the analysis to consider other commodity currencies, aside from the Chilean peso. It would be also interesting to explore if this predictive relationship survives at longer horizons and if it works well with other exchange rate fundamentals.

\section{References}

1. Buncic D. and C. Moretto (2015). Forecasting copper prices with dynamic averaging and selection models. North American Journal of Economics and Finance 33 (2015) $1-38$.

2. Campbell, J.Y. and R. J. Shiller (1987). Cointegration and Tests of Present Value Models, Journal of Political Economy, 1987, 95 (5), 1062-88.

3. Chen Y., K. Rogoff and B. Rossi (2010) Can Exchange Rates Forecast Commodity Prices?. The Quarterly Journal of Economics, August 2010, 125 (3), 1145-1194.

4. Chen Y., K. Rogoff and B. Rossi (2014) Can Exchange Rates Forecast Commodity Prices? An Update, manuscript, February 2014.

5. Chen Y., K. Rogoff and B. Rossi (2011) Predicting Agri-Commodity Prices: An Asset Pricing Approach, World Uncertainty and the Volatility of Commodity Markets, ed. B. Munier, IOS, 2011.

6. Ciner C. (2017). Predicting white metal prices by a commodity sensitive exchange rate. International Review of Financial Analysis 52, 309-315.

7. Clark T. E. and M. W. McCracken (2001). Tests of equal forecast accuracy and encompassing for nested models. Journal of Econometrics, 105(1), 85-110.

8. Clark T.E. and K.D. West (2006). Using Out-of-Sample Mean Squared Prediction Errors to Test the Martingale Difference Hypothesis. Journal of Econometrics 135: 155-186. 
9. Cowan K, D. Rappoport and J. Selaive (2007). High frequency dynamics of the exchange rate in Chile. Central Bank of Chile Working Papers $\mathrm{N}^{\circ}$ 433, Novembee 2007.

10. Engel C. and K. D. West (2005). Exchange Rates and Fundamentals. Journal of Political Economy, June 2005, 113 (3), 485-517

11. Gargano A. and A. Timmermann (2014) Forecasting Commodity Price Indexes Using Macroeconomic and Financial Predictors. International Journal of Forecasting 30, 825-843.

12. Goyal A. and I. Welch (2008). A comprehensive look at the empirical performance of equity premium prediction. Review of Financial Studies, 21(4), 1455-1508.

13. Groen J. and P. Pesenti. (2011). Commodity prices, commodity currencies, and global economic developments. In T. Ito, \&A. K. Rose (Eds.), (Vol. 20) Commodity prices and markets, NBER - East Asia seminar on economics (pp. 15-42). University of Chicago Press.

14. Ko Hsiu-Hsin and M. Ogaki (2015). Granger causality from exchange rates to fundamentals: What does the bootstrap test show us? International Review of Economics and Finance 38 198-206

15. Lof M. and H. Nyberg (2017). Noncausality and the commodity currency hypothesis. Energy Economics 65 (2017) 424-433.

16. Meese R. and K. Rogoff. (1983). Empirical Exchange Rate Models of the Seventies. Do They Fit Out-of-Sample? Journal of International Economics 14: 3-24.

17. Newey, W. and K.D. West. (1987). A Simple, Positive Semi-Definite, Heteroskedasticity and Autocorrelation Consistent Covariance Matrix. Econometrica, 55(3), 703-708.

18. Newey, W. and K.D. West. (1994) Automatic Lag Selection in Covariance Matrix Estimation. The Review of Economic Studies. 61(4): 631-53.

19. Pincheira P. (2018). Interventions and inflation expectations in an inflation targeting economy. Economic Analysis Review, forthcoming.

20. Pincheira P. and N. Hardy (2018). Forecasting Base Metal Prices with Commodity Currencies, Available at SSRN: https://ssrn.com/abstract $=3095448$

21. Roberts, M. (2008). Synchronization and Co-movement of Metal Prices. Minerals \& Energy, 23 (3), 105-118.

22. Roberts, M. (2009). Duration and Characteristics of Metal Price Cycles. Resources Policy, 34 (3), 87-102.

23. Rossen, A. (2015). What are metal prices like? Co-movement, price cycles and long-run trends, Hamburg Institute of International Economics Working Paper 155.

24. West K.D. and K.F. Wong (2014). A factor model for co-movements of commodity prices. Journal of International Money and Finance 42 (2014) 289-309

25. West K.D. (2006). Forecast Evaluation. In Handbook of Economic Forecasting Volume 1. G. Elliot, C. Granger and A. Timmermann editors. Elsevier. 


\section{Appendix A. Descriptive Statistics}

Table A1: Descriptive Statistics of Monthly Returns of our Variables

\begin{tabular}{lccccccccc}
\hline & \multicolumn{7}{c}{ Sample Period: October $2001-J u n e ~ 2017$} \\
\hline Mean & Aluminum & Copper & Lead & Nickel & Tin & Zinc & Lmex & Clp & SEE \\
\hline Median & 0.0019 & 0.0074 & 0.0079 & 0.0029 & 0.0088 & 0.0063 & 0.0053 & -0.0002 & -0.0003 \\
\hline Max & 0.0052 & 0.0140 & 0.0074 & -0.0009 & 0.0055 & 0.0122 & 0.0095 & -0.0033 & 0.0000 \\
\hline Min & 0.1688 & 0.2709 & 0.3085 & 0.3677 & 0.2439 & 0.3089 & 0.2088 & 0.1613 & 0.0929 \\
\hline Standard Deviation & -0.2348 & -0.3352 & -0.3716 & -0.4329 & -0.3008 & -0.3143 & -0.2936 & -0.0975 & -0.0535 \\
\hline \hline
\end{tabular}

Source: Authors' elaboration.

\section{Appendix B. Forecasting Base Metal Prices with Chilean Exchange Rates}

Tables B1-B3 next show results of the ENCNEW test of Clark and McCracken (2001) when evaluating if Chilean exchange returns have the ability to predict base metals returns. We consider the same three benchmarks as in the main body of this paper: an $\operatorname{AR}(1)$, a Random Walk with drift (RW), and a driftless random walk (DRW). Table B1 shows results when the number of one-step-ahead forecasts is three times the number of observations in our rolling estimation windows $(\pi \equiv P / R=3)$. Table B2 is similar to Table B1 but reports results when the number of one-step-ahead forecasts is the same as the number of observations used in our rolling estimation window $(\pi \equiv P / R=1)$. Finally, in Table B3 we consider a situation in which the number of one-step-ahead forecasts is $40 \%$ of the number of observations used in our rolling estimation windows $(\pi \equiv P / R=0.4)$. Our specifications are given in Table B4.

Table B1: Forecasting Base Metals Returns with Returns of the Chilean Peso

Out-of-sample analysis in rolling windows of size $\mathrm{R}=48,(\pi \equiv P / R=3)$

\begin{tabular}{c|cccccccc}
\hline \multicolumn{2}{c}{$(1)$} & $(2)$ & $(3)$ & $(4)$ & $(5)$ & $(6)$ & $(7)$ & $(8)$ \\
\hline Benchmark Model & aluminum & copper & lead & nickel & tin & zinc & lmex \\
\hline AR(1) & $4.97^{* *}$ & 1.84 & $3.03^{*}$ & -2.08 & -1.63 & 1.50 & $3.33^{* *}$ \\
\hline RW & $5.02^{* *}$ & $3.78^{* *}$ & 1.17 & -2.28 & -1.94 & $2.95^{*}$ & $2.92^{*}$ \\
\hline DRW & $4.73^{* *}$ & $4.39^{* *}$ & 2.21 & -1.94 & -2.07 & $2.99^{*}$ & $3.29^{*}$ \\
\hline \hline
\end{tabular}

$10 \%, 5 \%$ and $1 \%$ critical values are 2.322, 3.444 and 5.976 respectively for ENCNEW for one excess parameter.

$\mathrm{P}$ representes the number of one-step-ahead forecasts, $\mathrm{R}$ the sample size of the rolling estimation windows.

The AR(1) benchmark corresponds to model 1 in Table B4 when the coefficient associated to the Chilean Peso (ER)

is set to zero. Similarly, the RW and DRW benchmarks correspond to models 2 and 3 in Table B4,

respectively, when the coefficient associated to the Chilean peso is set to zero.

$$
\begin{gathered}
{ }^{*} \mathrm{p}<10 \%,{ }^{* *} \mathrm{p}<5 \%,{ }^{* * *} \mathrm{p}<1 \% \\
\text { Source: Authors' elaboration. }
\end{gathered}
$$


Table B2: Forecasting Base Metals Returns with Returns of the Chilean Peso Out-of-sample analysis in rolling windows of size $\mathrm{R}=95,(\pi \equiv P / R=1)$

\begin{tabular}{c|cccccccc}
\hline \multicolumn{2}{c}{$(1)$} & $(2)$ & $(3)$ & $\begin{array}{c}(4) \\
\text { ENCNEW }\end{array}$ & $(5)$ & $(6)$ & $(7)$ & $(8)$ \\
\hline Benchmark Model & aluminum & copper & lead & nickel & tin & zinc & lmex \\
\hline AR(1) & $2.50^{* *}$ & 0.73 & 0.32 & $2.21^{* *}$ & -0.22 & $1.31^{*}$ & $2.19^{* *}$ \\
\hline RW & 0.54 & $1.91^{* *}$ & -1.09 & $1.65^{*}$ & -0.28 & 0.43 & $1.58^{*}$ \\
\hline DRW & 0.73 & $2.22^{* *}$ & -1.01 & $1.85^{*}$ & -0.39 & 0.54 & $1.82^{*}$ \\
\hline \hline
\end{tabular}

$10 \%, 5 \%$ and $1 \%$ critical values are 1.210, 1.946 and 3.676 respectively for ENCNEW for one excess parameter.

$\mathrm{P}$ representes the number of one-step-ahead forecasts, $\mathrm{R}$ the sample size of the rolling estimation windows.

The AR(1) benchmark corresponds to model 1 in Table B4 when the coefficient associated to the Chilean Peso (ER)

is set to zero. Similarly, the RW and DRW benchmarks correspond to models 2 and 3 in Table B4, respectively, when the coefficient associated to the Chilean Peso is set to zero.

$$
\begin{gathered}
* \mathrm{p}<10 \%,{ }^{*} \mathrm{p}<5 \%,{ }^{* * *} \mathrm{p}<1 \% \\
\text { Source: Authors' elaboration. }
\end{gathered}
$$

Table B3: Forecasting Base Metals Returns with Returns of the Chilean Peso Out-of-sample analysis with rolling windows of size $\mathrm{R}=136(\pi \equiv P / R=0.4)$

\begin{tabular}{c|cccccccc}
\hline \multicolumn{2}{c}{$(1)$} & $(2)$ & $(3)$ & $\begin{array}{c}(4) \\
\text { ENCNEW }\end{array}$ & $(5)$ & $(6)$ & $(7)$ & $(8)$ \\
\hline Benchmark Model & aluminum & copper & lead & nickel & tin & zinc & lmex \\
\hline AR(1) & -0.10 & $1.99^{* *}$ & $1.08^{*}$ & $0.98^{*}$ & $0.15^{*}$ & 0.40 & $1.98^{* *}$ \\
\hline RW & -1.09 & $3.70^{* * *}$ & 0.02 & 0.74 & -0.07 & 0.46 & $2.55^{* * *}$ \\
\hline DRW & -1.29 & $2.89^{* * *}$ & -0.60 & 0.70 & 0.01 & 0.11 & $1.93^{* *}$ \\
\hline \hline
\end{tabular}

$10 \%, 5 \%$ and $1 \%$ critical values are $0.764,1.161$ and 2.278 respectively for ENCNEW for one excess parameter.

$\mathrm{P}$ representes the number of one-step-ahead forecasts, $\mathrm{R}$ the sample size of the rolling estimation windows.

The AR(1) benchmark corresponds to model 1 in Table B4 when the coefficient associated to the Chilean Peso (ER)

is set to zero. Similarly, the RW and DRW benchmarks correspond to models 2 and 3 in Table B4, respectively, when the coefficient associated to the Chilean Peso is set to zero.

$$
{ }^{*} \mathrm{p}<10 \%,{ }^{* *} \mathrm{p}<5 \%, * * * \mathrm{p}<1 \%
$$

Source: Authors' elaboration.

Table B4: Specifications used in Tables B1-B3

\begin{tabular}{ll}
\hline 1: & $\Delta \ln \left(C P_{t}\right)=c+\beta \Delta \ln \left(E R_{t-1}\right)+\rho \Delta \ln \left(C P_{t-1}\right)+u_{1 t}$ \\
2: $\quad \Delta \ln \left(C P_{t}\right)=c+\beta \Delta \ln \left(E R_{t-1}\right)+u_{2 t}$ \\
$\frac{\text { 3: } \quad \Delta \ln \left(C P_{t}\right)=\beta \Delta \ln \left(E R_{t-1}\right)+u_{3 t}}{\text { Source: Authors' elaboration }}$
\end{tabular}


where

$$
\begin{aligned}
\Delta \ln \left(C P_{t}\right) & \equiv \ln \left(C P_{t}\right)-\ln \left(C P_{t-1}\right) \\
\Delta \ln \left(E R_{t}\right) & \equiv \ln \left(E R_{t}\right)-\ln \left(E R_{t-1}\right)
\end{aligned}
$$

$C P_{t}$ stands for "Commodity Price" and represents the generic predictand at time $t$, which in our case represents aluminum, copper, lead, nickel, tin, zinc and the LME Index. Similarly, $E R_{t}$ represents the Chilean peso. The null hypothesis is simply

$$
H_{0}: \beta=0
$$

\section{Appendix C. The Chilean Exchange Rate is Mostly Overshadowed by Expec- tations}

Tables C1-C3 next show results of the ENCNEW test of Clark and McCracken (2001) when evaluating if Chilean peso returns have additional information to that already contained in exchange rate expectations to forecast base metal returns. We consider the models described in Table 2 in the main body of the paper and focus on the following null hypothesis:

$$
H_{0}: \gamma=0
$$

Table $\mathrm{C} 1$ shows results when the number of forecasts is three times the number of observations in our rolling estimation windows $(\pi \equiv P / R=3)$. Table $\mathrm{C} 2$ is similar to Table $\mathrm{C} 1$ but reports results when the number of forecasts is the same as the number of observations used in our rolling estimation window $(\pi \equiv P / R=1)$. Finally, in Table C3 we consider a situation in which the number of forecasts is $40 \%$ of the number of observations used in our rolling estimation windows $(\pi \equiv P / R=0.4)$. 
Table C1: Forecasting Base Metals with the Chilean Peso

Benchmarks include one lag of exchange rate expectations returns

Out-of-sample analysis in rolling windows of size $\mathrm{R}=48,(\pi \equiv P / R=3)$

\begin{tabular}{c|cccccccc}
\hline \multicolumn{1}{c}{$(1)$} & $(2)$ & $(3)$ & $(4)$ & $(5)$ & $(6)$ & $(7)$ & $(8)$ \\
\hline Benchmark Model & aluminum & copper & lead & nickel & tin & zinc & lmex \\
\hline $\mathrm{AR}(1)+\mathrm{d} \log (\mathrm{SEE}(-1))$ & -1.68 & -0.56 & -1.35 & -0.68 & 1.46 & -0.54 & -0.78 \\
\hline $\mathrm{RW}+\mathrm{d} \log (\mathrm{SEE}(-1))$ & -1.10 & -0.43 & -0.91 & -0.99 & $3.84^{* *}$ & -0.08 & -1.44 \\
\hline $\mathrm{DRW}+\mathrm{d} \log (\mathrm{SEE}(-1))$ & -1.29 & -0.44 & -0.7 & -0.84 & $3.31^{*}$ & -0.07 & -1.48 \\
\hline \hline
\end{tabular}

$10 \%, 5 \%$ and $1 \%$ critical values are 2.322, 3.444 and 5.976 respectively for ENCNEW for one excess parameter.

$\mathrm{P}$ representes the number of one-step-ahead forecasts, $\mathrm{R}$ the sample size of the rolling estimation windows.

The AR(1) benchmark corresponds to model 1 in Table B4 when the coefficient associated to the Chilean Peso (ER)

is set to zero. Similarly, the RW and DRW benchmarks correspond to models 2 and 3 in Table B4, respectively, when the coefficient associated to the Chilean peso is set to zero. d $\log (\operatorname{SEE}(-1))$ represents the first lag of the Survey of Economic Expectations returns.

$$
\begin{gathered}
* \mathrm{p}<10 \%,{ }^{* *} \mathrm{p}<5 \%,{ }^{* *} \mathrm{p}<1 \% \\
\text { Source: Authors' elaboration. }
\end{gathered}
$$

Table C2: Forecasting Base Metals Returns with Returns of the Chilean Peso Benchmarks include one lag of exchange rate expectations returns Out-of-sample analysis in rolling windows of size $\mathrm{R}=95,(\pi \equiv P / R=1)$

\begin{tabular}{c|cccccccc}
\hline \multicolumn{2}{c}{$(1)$} & $(2)$ & $(3)$ & $\begin{array}{c}(4) \\
\text { ENCNEW }\end{array}$ & $(5)$ & $(6)$ & $(7)$ & $(8)$ \\
\hline Benchmark Model & aluminum & copper & lead & nickel & tin & zinc & lmex \\
\hline $\mathrm{AR}(1)+\mathrm{d} \log (\mathrm{SEE}(-1))$ & -0.25 & -0.52 & -1.95 & 0.13 & 1.17 & -0.42 & -0.13 \\
\hline $\mathrm{RW}+\mathrm{d} \log (\mathrm{SEE}(-1))$ & -0.16 & -0.54 & -1.94 & 0.04 & $1.38^{*}$ & -0.72 & -0.51 \\
\hline $\mathrm{DRW}+\mathrm{d} \log (\mathrm{SEE}(-1))$ & -0.16 & -0.53 & -1.97 & 0.07 & $1.41^{*}$ & -0.71 & -0.51 \\
\hline \hline
\end{tabular}

$10 \%, 5 \%$ and $1 \%$ critical values are 1.210, 1.946 and 3.676 respectively for ENCNEW for one excess parameter.

$\mathrm{P}$ representes the number of one-step-ahead forecasts, $\mathrm{R}$ the sample size of the rolling estimation windows.

The AR(1) benchmark corresponds to model 1 in Table B4 when the coefficient associated to the Chilean Peso (ER) is set to zero. Similarly, the RW and DRW benchmarks correspond to models 2 and 3 in Table B4, respectively, when the coefficient associated to the Chilean Peso is set to zero. $d \log (\operatorname{SEE}(-1))$ represents the first lag of the Survey of Economic Expectations returns.

$$
\begin{gathered}
* \mathrm{p}<10 \%,{ }^{* *} \mathrm{p}<5 \%,{ }^{* * *} \mathrm{p}<1 \% \\
\text { Source: Authors' elaboration. }
\end{gathered}
$$


Table C3: Forecasting Base Metals Returns with Returns of the Chilean Peso

Benchmarks include one lag of exchange rate expectations returns

Out-of-sample analysis with rolling windows of size $\mathrm{R}=136(\pi \equiv P / R=0.4)$

\begin{tabular}{c|cccccccc}
\hline \multicolumn{2}{c}{$(1)$} & $(2)$ & $(3)$ & $(4)$ & $(5)$ & $(6)$ & $(7)$ & $(8)$ \\
\hline Benchmark Model & aluminum & copper & lead & nickel & tin & zinc & lmex \\
\hline $\mathrm{AR}(1)+\mathrm{d} \log (\mathrm{SEE}(-1))$ & -0.26 & 0.40 & -0.41 & -0.29 & 0.12 & -0.31 & 0.16 \\
\hline $\mathrm{RW}+\mathrm{d} \log (\mathrm{SEE}(-1))$ & -0.02 & 0.68 & -0.34 & -0.54 & -0.83 & -0.32 & 0.09 \\
\hline $\mathrm{DRW}+\mathrm{d} \log (\mathrm{SEE}(-1))$ & -0.02 & 0.63 & -0.37 & -0.55 & -0.69 & -0.33 & 0.07 \\
\hline \hline
\end{tabular}

$10 \%, 5 \%$ and $1 \%$ critical values are $0.764,1.161$ and 2.278 respectively for ENCNEW for one excess parameter.

$\mathrm{P}$ representes the number of one-step-ahead forecasts, $\mathrm{R}$ the sample size of the rolling estimation windows.

The AR(1) benchmark corresponds to model 1 in Table B4 when the coefficient associated to the Chilean Peso (ER)

is set to zero. Similarly, the RW and DRW benchmarks correspond to models 2 and 3 in Table B4,

respectively, when the coefficient associated to the Chilean Peso is set to zero.

$\operatorname{d} \log (\operatorname{SEE}(-1))$ represents the first lag of the Survey of Economic Expectations returns.

${ }^{*} \mathrm{p}<10 \%, * * \mathrm{p}<5 \%, * * * \mathrm{p}<1 \%$

Source: Authors' elaboration.

With only four exceptions, Tables C1-C3 show that the predictive ability of Chilean exchange rate is mostly overshadowed by the presence of exchange rate expectations. 